\title{
EFEITO DO ULTRASSOM TERAPÊUTICO NA LIBERAÇÃO, PERMEAÇ̃̃O E RETENÇÃO DE ÁCIDO KÓJICO EM SISTEMA DE DIFUSÃO VERTICAL
}

\author{
João Alberto TASSINARY*, Luana Nicolau ROGÉRI, Bárbara SCHMITT, Fernanda MARDER, Giovana \\ SINIGAGLIA, Jairo HERBELE, Maurício HILGEMANN \& Simone STÜLP
}

Universidade do Vale do Taquari. Lajeado, Rio Grande do Sul, Brasil.

*Autor correspondente: tassinary@gmail.com

DOI: http://dx.doi.org/10.18571/acbm.152

\section{RESUMO}

A administração transdérmica de ativos terapêuticos oferece muitas vantagens sobre outras vias de administração, dentre as quais destacam-se o potencial de eficácia superior e efeitos colaterais mínimos. No entanto, o sistema tegumentar é caracterizado como barreira praticamente impermeável. Neste sentido, pesquisas tem se voltado a buscar recursos que visam ampliar a permeação de substâncias sobre a pele, como a fonoforese. Esta técnica baseia-se na associação de medicamento ou cosmético ao ultrassom terapêutico. Entre os princípios farmacologicamente ativos com potencial de associação à técnica de fonoforese destaca-se o ácido kójico, que é amplamente utilizado na Biomedicina Estética, principalmente por sua ação antioxidante e hipopigmentante. Neste sentido, o objetivo deste estudo foi investigar a liberação e permeação do gel contendo ácido kójico $10 \%$ frente à aplicação de fonoforese in vitro. O estudo de liberação e permeação do ácido kójico foi realizado a partir de uma célula de difusão vertical tipo Franz, com membrana de acetato de celulose e biomembrana de pele suína. Foram realizadas análises com e sem aplicação de ultrassom terapêutico, e os resultados mostraram que a técnica de fonoforese amplia em 19\% a liberação do ácido kójico para o meio receptor, bem como, em 50\% a retenção do ativo no estrato córneo e em $121 \%$ a sua permeação em 20 minutos de aplicação.

Palavras chave: Ultrassom; Ácido kójico; Permeação.

\begin{abstract}
Effect of ultrasound therapeutic in the release, permeation and retention of Acid Kojic in broadcasting system vertical. Transdermal therapeutic active offers many advantages over other routes of administration, among these we highlight a potential higher efficacy and minimal side effects. However, the integumentary system is characterized as a substantially impermeable barrier. In this sense, research has turned to look for features that aim to enhance the permeation of substances on the skin, such as phonophoresis. This technique is based on the combination of the product or cosmetic with ultrasound. Among the principles pharmacologically active association with potential to phonophoresis technique highlights the kojic acid, which is widely used in biomedicine Aesthetics mainly for its antioxidant and hipopigmentante. In this sense the objective of this study was to investigate the release and permeation of the gel Kojic Acid 10\% compared to the application of phonophoresis in vitro. The release study and permeation of kojic acid was performed using a vertical Franz type diffusion cells, with cellulose acetate membrane and skin from porcine biomembrane. Analyses were performed with and without application of therapeutic ultrasound, and the results showed that the phonophoresis technique extends the release of kojic acid for the receiving means, as well as the retention of the active in the stratum corneum and its permeation at 20 minutes.
\end{abstract}

Keywords: Ultrasound; Kojic Acid; Permeation. 


\section{Introdução}

O sistema tegumentar é composto basicamente pelo folículo pilossebáceo, aparelho ungueal, glândulas e pele, sendo está última subdividida em camadas como hipoderme, derme e epiderme (PRENTICIE, 2004). Dentre as suas inúmeras funções o tegumento proporciona proteção ao corpo contra o meio externo, abrasões, perda de líquido, substâncias nocivas e microrganismos invasores. Considerada como superfície de revestimento do corpo, a pele é indispensável por isolar os componentes orgânicos do seu exterior (GUIRRO e GUIRRO, 2002).

No entanto, nas últimas décadas, pesquisadores vem demonstrando que a pele intacta pode ser usada como uma porta de administração sistêmica ou como uma via de administração de princípios ativos. A administração transdérmica de fármacos oferece muitas vantagens sobre outras vias de administração, como, por exemplo, um potencial de eficácia superior e efeitos colaterais mínimos. As vantagens culminam ainda na efetividade de tratamento a partir da facilidade de aplicação e competente entrega do princípio ativo ao tecido alvo. Neste sentido, tratamentos tópicos estão sendo cada vez mais incluídos nas condutas clínicas de profissionais da área da saúde (BANGA, 2011; CARTER et al. 2013).

Consequentemente, inúmeras pesquisas intimamente comprometidas com a procura de melhores resultados para tratamentos, que vão desde doenças músculo esqueléticas até disfunções estéticas, tem buscado formas de ampliar a permeação de princípios ativos através da pele. Entre estes recursos que visam ampliar a permeação de substâncias sobre a pele destaca-se a fonoforese, que é uma técnica baseada na associação do medicamento ou cosmético ao ultrassom terapêutico (TASSINARY et al. 2011).

Os aparelhos de ultrassom foram inicialmente produzidos através de um cristal de quartzo vibrante, submetido a uma corrente de alta frequência. Atualmente, utiliza-se cristal cerâmico sintético na sua fabricação em razão de sua durabilidade e eficiência em converter corrente elétrica em vibrações mecânicas, fundamentais para o funcionamento do equipamento, eis que essas vibrações acionam as partículas que estão presentes no meio (FUIRINI, et al. 2002).

Na prática clínica o ultrassom é utilizado nas mais diversas áreas da reabilitação do corpo humano. Estudos têm mostrado sua eficácia no tratamento de lesões músculos esqueléticas e também da pele. Segundo a literatura, quando a onda sonora entra em contato com as interfaces teciduais do paciente, podem ocorrer efeitos nas células e tecidos essencialmente por dois mecanismos físicos: térmico e não-térmico (KITCHEN, 2003).

Segundo Kitchen e Basin (1998), dentre os mecanismos físicos envolvidos na produção dos efeitos terapêuticos, estão a cavitação, a corrente acústica e as ondas estacionárias. A partir destes fenômenos físicos, profissionais das mais diversas áreas vêm aplicando substâncias farmacologicamente ativas através da pele, para o interior dos tecidos cutâneos, sob influência da onda sônica terapêutica. Muitos princípios ativos são absorvidos pela pele lentamente e a vibração sonora de alta frequência tem a finalidade de acelerar este processo. (LOW E REED, 2001).

Teoricamente, a aplicação da fonoforese é possível devido à utilização das forças físicas existentes no campo do ultrassom. Assim, tem se buscado princípios farmacologicamente ativos que possam ser associados com sucesso a essa técnica, dentre os quais destaca-se o ácido kójico, que é amplamente utilizado na Biomedicina Estética, principalmente por induzir a redução da eumelanina atuando positivamente em hiperpigmentações cutâneas e ainda possuir ação antiirritante (MAIA, 1995).

O ácido kójico é descrito pela literatura como uma substância natural produzida por vários fungos e bactérias, dentre elas espécies de Aspergillus, Penicillium e Acetobacter. Dentro de suas várias atividades benéficas já comprovadas cientificamente destacam-se a ação antimicrobiana e quelante de íons cobre, sendo esta última responsável pela inativação da tirosinase e, consequentemente, pela ação inibidora na formação de melanina (DRAELOS, 2008). Usualmente 
a concentração máxima de ácido kójico em cremes é de 5\%, pois em excesso pode causar efeitos colaterais severos como dermatite, eritema e hiperpigmentação (YANG, ZHANG, 2007).

Entretanto, é questionável se essa força é suficiente para carrear as moléculas até o ponto alvo. Outrossim, comumente é arriscado determinar se o efeito biológico de uma onda aplicada topicamente é resultado de um efeito sistêmico, ou da sua ação direta no tecido alvo subjacente. Contudo, é aceitável o fato de que a fonoforese não depende apenas dos parâmetros ajustados pela terapeuta no ultrassom, mas também pela natureza da molécula do medicamento propriamente dito. Dessa forma, são necessárias pesquisas de fármacos que possam ser usados de forma mais efetiva nesta técnica (MITRAGOTRI e KOST, 2004).

Sendo assim, o objetivo deste estudo foi investigar a liberação e permeação do gel contendo ácido kójico 5\% frente à aplicação de fonoforese in vitro, para que seja possível quantificar a real eficácia do seu emprego terapêutico.

\section{Materiais e Métodos}

\subsection{Reagentes}

As amostras utilizadas nos testes de liberação e permeação foram obtidas pela adição de ácido kójico $10 \%$ (SIGMA-ALDRICH) em gel condutor marca RMC - ácido carboxivinílico/Carbopol - (Mercur). No compartimento receptor foi utilizado água: álcool metílico (1:1).

\subsection{Aplicação do ultrassom terapêutico in vitro}

O aparelho de ultrassom terapêutico utilizado para a pesquisa foi fornecido pela empresa DGM eletrônica Ltda., sendo este com frequência de $3 \mathrm{MHz}, 1,0 \mathrm{~W} / \mathrm{cm}^{2}$ de potência e ciclo contínuo.

\subsection{Análise da liberação do ácido kójico}

O estudo de liberação do ácido kójico foi realizado em uma célula de difusão vertical tipo Franz, com solução receptora de água e álcool metílico com proporção de 1:1, suficiente para manter a homogeneidade da amostra. Com a finalidade de separar o meio doador do receptor foi disposta uma membrana de acetato de celulose (Sartorius Stedim Biotech) com porosidade de 0,45 $\mu \mathrm{m}$. Para a adequação do experimento às condições biológicas, a célula foi acoplada a um banho termostatizado a $37^{\circ} \mathrm{C}$, a fim de simular a temperatura corpórea. Utilizou-se também um agitador magnético e, dentro do compartimento receptor, foi colocada uma barra magnética com o objetivo de mantes a homogeneidade da amostra.

As análises de liberação do ácido kójico foram realizadas em triplicatas com e sem (controle) a aplicação do ultrassom terapêutico (US) nos tempos de 10 e 20 minutos. A sua quantificação foi feita em um espectrofotômetro Cary 100 Bio UV/Vis, no comprimento de onda de $269 \mathrm{~nm}$.

\subsection{Análise da retenção e permeação do Ácido Kójico através da biomembrana de pele de suíno}

Os ensaios in vitro de permeação do ácido kójico foram realizados com o mesmo sistema de difusão vertical, com exceção de que a membrana de acetato de celulose foi substituída por pele de suíno. Utilizou-se a referida biomembrana, pois segundo Pellet et al. (1997), esta possui propriedades similares às da pele humana. A quantificação do ácido kójico foi feita por espectrofotometria, no comprimento de onda de $269 \mathrm{~nm}$. 
No caso dos ensaios de retenção, seguindo metodologia descrita pela literatura, utilizou-se um sistema de 12 fitas de $3 \mathrm{~cm}$ de comprimento por $1 \mathrm{~cm}$ de largura, sendo que a primeira foi descartada e as outras 11 foram utilizadas para a realização da análise do estrato córneo. Todas as fitas foram posicionadas no mesmo local, no qual se simulou um processo de epilação para realizar a retirada do estrato córneo. Posteriormente as fitas foram colocadas em $4 \mathrm{~mL}$ de uma solução de metanol e água (1:1), e expostas por 15 minutos a $37^{\circ} \mathrm{C}$ em banho termostatizado com o objetivo de simular a temperatura corpórea.

Ainda na avaliação de retenção da epiderme e derme, ambas foram separadas a partir de técnica cirúrgica e também colocadas em solução de $4 \mathrm{~mL}$ de metanol com água (1:1), seguindo a metodologia acima descrita para as fitas adesivas.

\subsection{Procedimentos para análise dos dados}

Para a quantificação do ácido kójico foi construída uma curva de calibração, a partir de soluções de ácido kójico em solução de água e metanol (1:1) em diferentes concentrações de x e $\mathrm{y} \%$. A reta obtida é descrita pela equação $y=0,00608+537,95079 x\left(\mathrm{R}^{2}=0,999\right)$, a qual foi utilizada para determinar a concentração de ácido kójico nas amostras. Os resultados foram expressos em média \pm erro padrão da média (EPM).

Utilizou-se o teste de Shapiro-Wilk para averiguar normalidade dos dados, e para os parâmetros com dois grupos, foi utilizado o teste $t$ de Student. Em todos os casos, os resultados foram considerados estatisticamente significativos quando $p<0,05$. Todas as análises estatísticas foram realizadas utilizando o software SPSS (Statistical Package for the Social Sciences) versão 18.0.

\section{Resultados}

Inicialmente, foi avaliado o efeito do ultrassom contínuo sobre a liberação do ácido kójico, nos tempos de 10 (FIGURA 1 - A) e 20 minutos (FIGURA 1 - B), em sistema de difusão vertical a partir do uso de membrana de acetato de celulose.

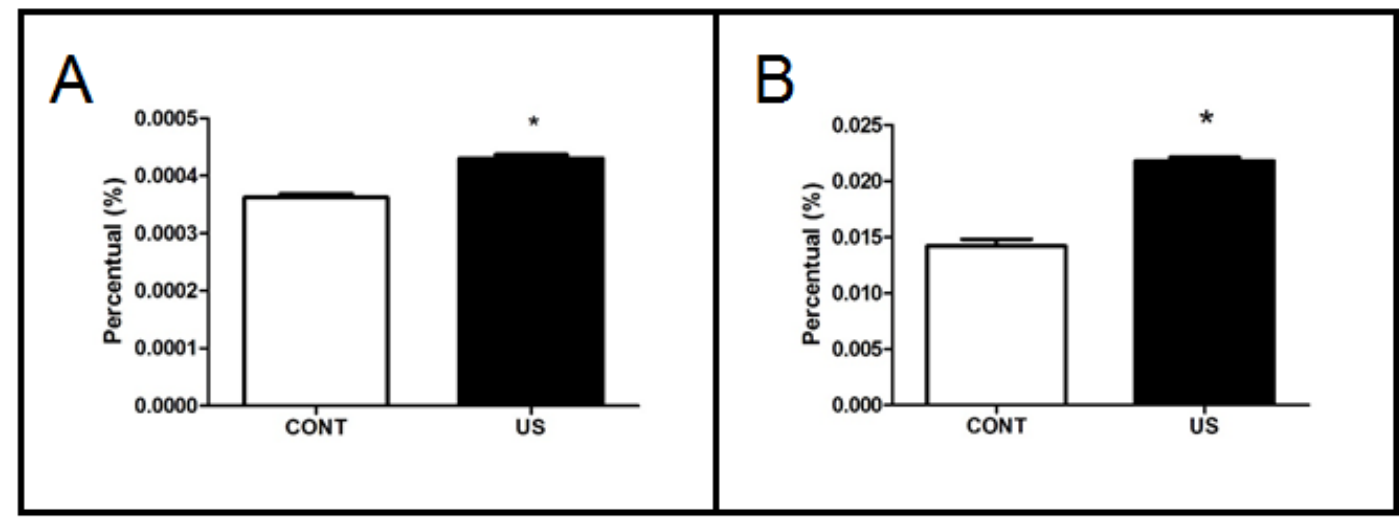

Figura 1: A) Análise da liberação do ácido kójico com e sem a utilização do ultrassom em modo contínuo no tempo de 10. B) Análise da liberação do ácido kójico com e sem a utilização do ultrassom em modo contínuo no tempo de 20 minutos. Comparação entre a liberação do ácido kójico. Dados expressos em \pm SEM. * p<0.05 vs controle.

Conforme a Figura 1, pode-se evidenciar que o ultrassom tem a capacidade de ampliar em 19\% a liberação do ácido kójico no tempo de 10 minutos, já no tempo de 20 minutos o ultrassom incrementou em 53\% a liberação do ácido kójico para o meio receptor conforme apresentado no gráfico B. 
Por conseguinte, avaliou-se a retenção do ácido kójico no estrato córneo, na epiderme e na derme, frente à utilização da fonoforese em sistema de difusão vertical, utilizando-se a biomembrana de pele suína. A figura 2 apresenta a retenção do ácido kójico no estrato córneo, nos grupo controle e ultrassom nos tempos de 10 e 20 minutos.

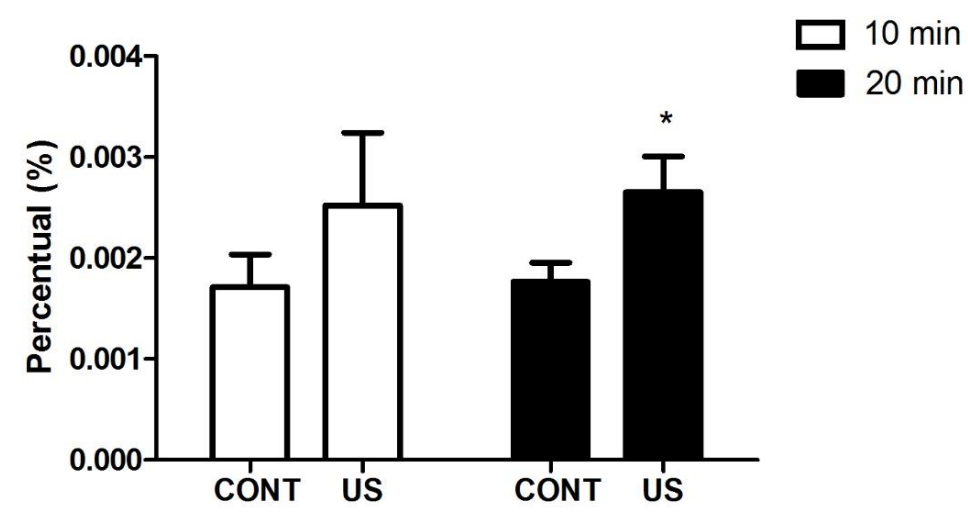

Figura 2: Gráfico comparando a retenção do ácido kójico no estrato córneo com e sem a aplicação da fonoforese nos tempos de 10 e 20 minutos. Dados expressos em \pm SEM, $*$ p $<0.05$ vs controle.

Os resultados da figura 2 mostram que no tempo de 10 minutos não existe diferença significativa em termos de retenção de ácido kójico no estrato córneo entre os grupos controle e ultrassom. No entanto, o ultrassom ampliou em 50\% a retenção do principio ativo no tempo de 20 minutos.

Na figura 3 tem-se a retenção do ácido kójico na epiderme nos tempos de 10 e 20 minutos com e sem a aplicação do ultrassom terapêutico. Conforme a figura, não existe diferença significativa em termos de retenção do ácido kójico na epiderme quando compara-se o do grupo controle ao tratado com ultrassom nos tempos de 10 e 20 minutos.

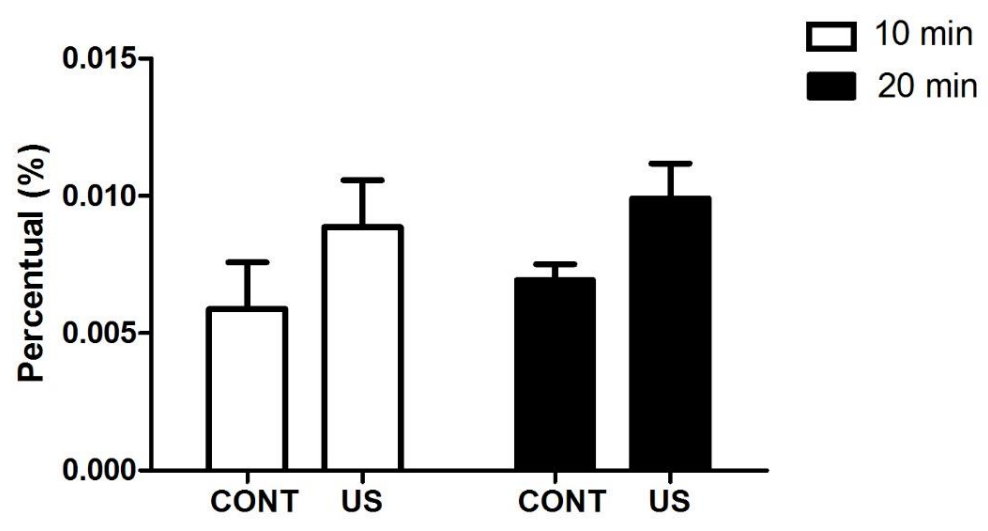

Figura 3: Concentração retida do ácido kójico na epiderme com e sem a aplicação do ultrassom terapêutico no modo contínuo nos tempos de 10 e 20 minutos. Dados expressos em média $\pm \mathrm{EPM}, * \mathrm{p}<0,05$ vs controle.

A figura 4 elucida a retenção do princípio ativo na derme frente a aplicação de fonoforese nos tempos de 10 e 20 minutos, mostrando que o ultrassom não amplia a retenção de ácido kójico na derme quando comparada ao grupo controle, sendo estes resultados identificados tanto nas análises de 10 quanto de 20 minutos. 


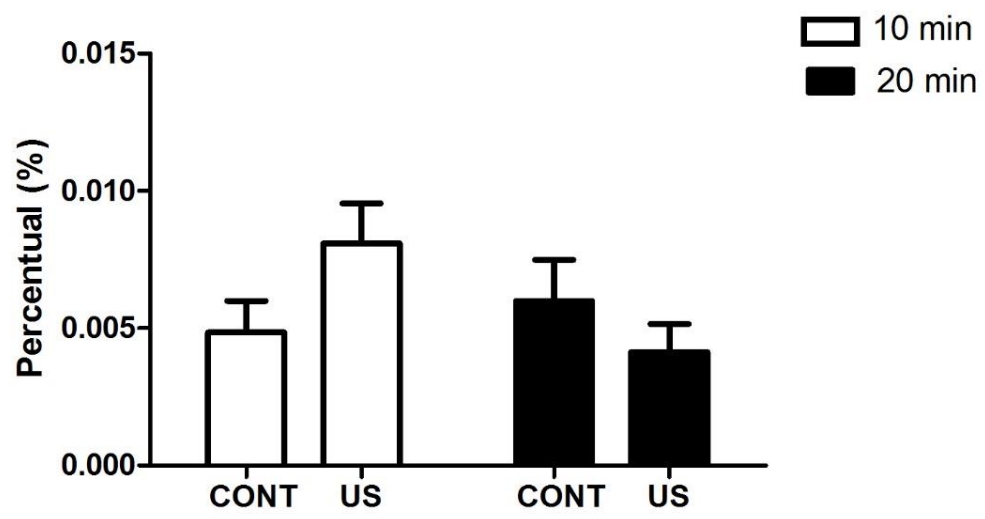

Figura 4: Percentual retido do princípio ativo na derme suína com e sem a utilização do ultrassom no modo contínuo. Dados expressos em media \pm $\mathrm{EPM}, * \mathrm{p}<0,05$ quando comparado ao grupo controle.

Por fim, avaliou-se a permeação do ácido kójico pela pele de suíno frente a aplicação do ultrassom terapêutico nos tempos de 10 e 20 minutos.

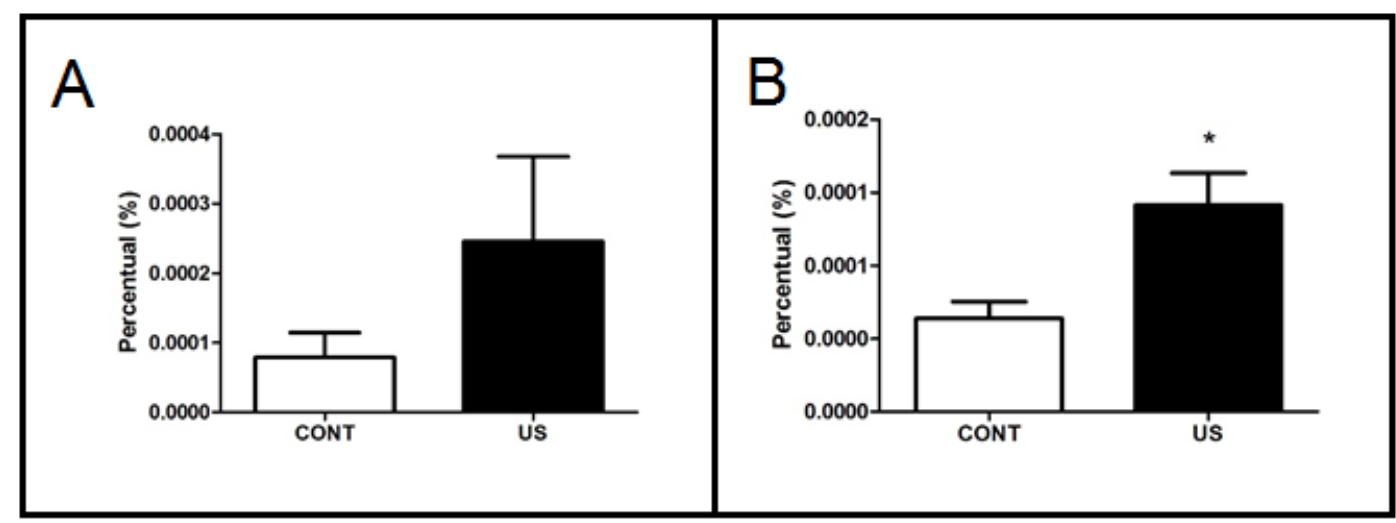

Figura 5: A) Análise da permeação do ácido kójico pela pele de suíno com e sem a aplicação do ultrassom terapêutico no tempo de 10 minutos. B) Análise da permeação do ácido kójico pela pele de suíno com e sem a aplicação do ultrassom terapêutico no tempo de 20 minutos. Dados expressos em média \pm EPM, *p<0,05 quando comparado ao grupo controle.

Os resultados mostraram que no tempo de 10 minutos não há diferença em termos de permeação do princípio ativo para o meio receptor quando comparado grupo controle e tratado com ultrassom (FIGURA 5 - A), em contrapartida, as ondas sonoras se mostraram facilitadoras da permeação transdérmica do ácido kójico no tempo de 20 minutos conforme mostrado figura 5 - B, sendo este incremento estimado em $121 \%$.

\section{Discussão}

O desenvolvimento de recursos que ampliam a liberação transdérmica de fármacos tem se intensificado nos últimos anos com o objetivo de superar problemas associados às propriedades de barreira da pele, melhorando assim, a liberação de ativos terapêuticos, principalmente os de alto peso molecular (SCHUETZ et al. 2006). Segundo Fortenbache e Maibach (2008) é fundamental que sejam desenvolvidos sistemas de liberação do ativo de seu respectivo veículo, para que se garanta, por consequência, maior penetração dos agentes terapêuticos no sistema tegumentar. Neste sentido, avaliou-se inicialmente a liberação do ácido kójico frente à exposição das ondas sonoras em sistema de difusão vertical com membrana de acetato de celulose. Os resultados 
mostram que o ultrassom terapêutico tem a capacidade de ampliar a liberação do princípio ativo para o meio receptor nos tempos de 10 e $20 \mathrm{~min}$ em 19 e $53 \%$, respectivamente.

Neste modelo experimental, o ultrassom tem a capacidade de incrementar a liberação de ácido kójico levando em consideração que a maioria dos fármacos aplicados na pele possui ação nas suas camadas mais profundas, e necessitam, portanto, permear o estrato córneo para chegar ao seu local de ação. E considerando a constituição e o efeito protetor do estrato córneo já anteriormente citados, vários fármacos podem apresentar dificuldades em atravessar essa barreira e atingir seu sítio de ação (FORTENBACH e MAIBACH, 2008). Sendo assim, avaliou-se a retenção do ácido kójico nas diferentes interfaces teciduais - estrato córneo, epiderme e derme com e sem aplicação do ultrassom, nos tempos de 10 e 20 minutos.

Os resultados de retenção mostraram que no tempo de 10 minutos não há diferença significativa entre os dois grupos em todas as interfaces teciduais investigadas. $\mathrm{O}$ mesmo ocorre no tempo de 20 minutos, com exceção do estrato córneo. Ao que tudo indica, o ultrassom tem a capacidade de apenas ampliar a retenção do ácido kójico no estrato córneo quando associado à técnica de fonoforese.

Por fim, avaliou-se o efeito do ultrassom na permeação in vitro do ácido kójico. A partir da comparação entre os grupos controle e tratado, ficou evidente que em 10 minutos não há diferença estatística. Por outro lado, no tempo de 20 minutos, o ultrassom ampliou em $121 \%$ a permeação do ácido kójico para o meio receptor.

Alguns autores descrevem que, embora seja complexo estabelecer diretamente os princípios que afetam a penetração cutânea de fármacos, alguns fatores podem ser destacados: concentração do fármaco, pois a quantidade de ativo que permeia a pele por unidade de superfície de área por intervalo de tempo aumenta à medida que a concentração do fármaco no veículo aumenta; tamanho da área de aplicação, pois teoricamente uma quantidade maior do fármaco é absorvida pela via cutânea quando a substância é aplicada numa área maior; grau de afinidade físico-química do fármaco com a pele; espessura tegumentar do local de aplicação; permanência da substância ativa sobre a pele, uma vez que, convencionalmente, quanto maior o período de permanência do medicamento sobre a pele, maior será a permeação e; por fim o tempo e intensidade de massagem sobre a pele, pois entende-se que o tempo e a intensidade de fricção ou massagem na aplicação tópica influenciam a quantidade de fármaco absorvida, já que, teoricamente, quanto maior o período e a intensidade de fricção, maior a permeação do mesmo (SCHUETZ et al. 2006).

Dentre os princípios supracitados que podem ter atuado diretamente no incremento da liberação, retenção e permeação do ácido kójico neste modelo experimental, cabe mencionar o item tempo de permanência da substância sobre a pele. Os resultados mostram que no tempo de 20 minutos os valores analisados são maiores que no de 10 minutos.

Outrossim, o fato de o ultrassom ter ampliado a liberação, a retenção no estrato córneo e também a permeação do ácido kójico, conforme descrito nos resultados, ele pode estar também diretamente relacionado aos fenômenos térmicos e físicos impressos pelas ondas sonoras cicladas no equipamento.

Outros estudos corroboram tais resultados. Pesquisas com moléculas de diferentes naturezas, porém utilizando este mesmo modelo experimental, evidenciaram que o ultrassom também tem a capacidade de ampliar a liberação e permeação de fármacos devido aos efeitos térmicos e físicos (SIMONIN, 1995; TASSINARY, et al. 2011; VALANDRO, et al. 2015).

Neste sentido, baseado no fato de que o ultrassom ciclado no modo contínuo ter a capacidade de ampliar a temperatura local (KITCHEN, 2003), reforça-se a hipótese de que a técnica de fonoforese aumenta a libertação de calor, o que por sua vez, incrementa a difusividade do ativo e a cinética do mesmo (SIMONIN, 1995)

Além da temperatura, cabe destacar os possíveis efeitos físicos benéficos do ultrassom para a técnica de fonoforese, como a corrente acústica e a cavitação. A corrente acústica caracteriza-se 
por um fluxo circulatório invariável devido ao torque de radiação e tem como subsequência a microcorrenteza, que desempenha sobrecarga viscosa sobre a membrana da célula e, portanto, pode aumentar a permeabilidade das membranas celulares e, consequentemente, ampliar a retenção e permeação de substâncias sobre a pele. Já a cavitação acústica, a partir da formação de cavidades gasosas colapsadas, tem a capacidade de atuar sobre o meio de acoplamento alterando características do veículo, e/ou também facilitando a sua permeação e retenção no sistema tegumentar (MITRAGOTRI e KOST, 2004).

\section{Conclusão}

O ultrassom terapêutico vem sendo utilizado como um importante recurso em procedimentos de reabilitação clínica. Considerando os efeitos oferecidos por este equipamento, os testes in vitro nos permitem entender os fenômenos que ocorrem durante a sua aplicação.

A administração transdérmica de princípios ativos terapêuticos oferece inúmeras vantagens sobre outras vias de administração. Como fase inicial para tal análise identificou-se a capacidade de liberação das substâncias. Os resultados sugerem que o ultrassom tem a capacidade de ampliar a liberação do ativo para o meio receptor nos tempos de 10 e 20 minutos em 19 e $53 \%$, respectivamente, além de incrementar a retenção do ácido kójico no estrato córneo em $50 \%$ e estimular sua permeação em $121 \%$ no tempo de 20 minutos.

\section{Referências}

BANGA, A.K. Transdermal and intradermal delivery of therapeutic agents - application of physical technologies. New York: CRC Press; 2011.

BIANCHETTI, P.; TASSINARY, J. A. F.; CERUTTI, D. G. U.; BARNES, D.; ETHUR, E. M.; STÜLP, S. Avaliação eletroquímica e espectrofotométrica de soluções de rutina submetidas a ultrassom terapêutico. Revista Liberato, v. 10, n. 14, p. 139-148, 2009.

CAMPOS, P.M.B.G. Manipulação magistral no tratamento de discromias. Cosmiatr. Méd. Estét., São Paulo, v. 2, n. 2, p. 35-39, 1995.

CARTER, S.G.; ZHU Z.; VARADI, G.; VEVES, A.; RIVIERE, J.E. Vasomodulation influences on the transdermal delivery of ibuprofen. Pharmaceutics, Drug Delivery and Pharmaceutical Technology, v. 102, n. 11, p. 4072-4078, 2013.

DRAELOS, Z.D. The cosmeceutical realm. Clin. Dermatol, v. 26, n. 6, p. 627-32, 2008.

FORTENBACH, B.S.; MAIBACH, H.I. Role of Physical Chemical Properties in Drug Relay into Skin Compartments. Skin Pharmacology and Physiology, n. 21, p.294-299, 2008.

FUIRINI, N. J.R.; LONGO, G.J. Ultra-som. 2. ed. Amparo: KLD - Biossistemas Equipamentos Eletrônicos Ltda. 2002.

GUIRRO, E.; GUIRRO, R. Fisioterapia Dermato-funcional. 3. ed. São Paulo: Manole, 2002.

LOW, J.; REED, A. Ultra-som terapêutico. In: Eletroterapia Explicada Princípios e Prática. 3.ed. São Paulo: Manole, 2001.

KITCHEN, S.; BAZIN, S. Eletroterapia de Clayton. 10. ed. São Paulo: Manole, 1998. 
KITCHEN, S. Eletroterapia: prática baseada em evidências. 11. ed. São Paulo: Manole, 2003.

MITRAGOTRI, S.; KOST, J. Low-frequency sonophoresis. A review. Advanced Drug Delivery Reviews, v. 56, p. 589-601, 2004.

PELLET, M. A.; ROBERTS, M. S.; HADGRAFT, J. Supersaturated solutions evaluated with an in vitro stratum corneum tape stripping. International Journal of Pharmaceutics, v. 151, p. 9198, 1997. PRENTICE, W.E. Modalidades Terapêuticas para Fisioterapeutas. 2. ed. Porto Alegre: Artmed, 2004.

SCHUETZ, Y.B.; CARRUPT, P.A.; NAIK A.; GUY, R.H.; KALIA, Y.N. Structureñ permeation relationships for the non-invasive transdermal delivery of cationic peptides by iontophoresis. European Journal of Pharmaceutical Sciences, v. 94, p. 2175-2182, 2006.

SIMONIN, J.P. On the mechanisms of in vitro and vivo phonophoresis. Journal Of Controlled Realease, n. 33, p. 125-141, 1995.

SIMONUB, J.P. On the mechanisms of in vitro and in vivo phonophoresis. Journal of Controlled Release, v. 33, p. 125-141, 1995.

TASSINARY, J. A.; BIANCHETTI, P.; REMPEL, C.; STÜLP, S. Avaliação dos efeitos do ultrassom terapêutico sobre a cafeína e verificação da liberação em sistema de difusão vertical. Quím. Nova, São Paulo, v. 34, n. 9, p. 1539-1543, 2011.

TASSINARY, J.A.; BIANCHETTI, P.; REMPEL, C.; STÜLP, S. Avaliação dos efeitos do ultrassom terapêutico sobre a cafeína e verificação da liberação em sistema de difusão vertical. Quim Nova, n. 34, n.9, p. 1539-1543, 2011.

VALANDRO, F.; TASSINARY, J. A. F.; BIANCHETTI, P.; SCHMITT, B.; BRESCIANI, L.; STÜLP, S. Avaliação da liberação da rutina associada ao ultrassom contínuo. Ciência e Natura, v.37, n.4, p. 678-683, 2015.

YANG, X.; ZHANG, H. Sensitive determination of kojic acid in foodstuffs using PVP (polyvinylpyrrolidone) modified acetylene black paste electrode. Food Chemistry, v. 102, p.1223-1227, 2007. 